\title{
A Review of Carbon dots (CDs) Application in Sensing and Removing Medical Waste
}

\author{
Ilham Alkian ${ }^{1,4}$,Heri Sutanto ${ }^{2,4, *}$, Bella Aprimanti Utami ${ }^{2}$, Inten Rafika Duri ${ }^{2}$, \\ Dewi Qurrota A'yuni ${ }^{3}, H$ Hadiyanto ${ }^{1,3}$ \\ ${ }^{1}$ Master Program of Environmental Science, School of Postgraduate Studies, Diponegoro University, \\ Semarang -Indonesia \\ ${ }^{2}$ Department of Physics, Faculty of Science and Mathematics, Diponegoro University, Semarang - \\ Indonesia \\ ${ }^{3}$ Department of Chemical Engineering, Faculty of Engineering, Diponegoro University, Semarang - \\ Indonesia \\ ${ }^{4}$ Smart Materials Research Center, Diponegoro University, Semarang -Indonesia
}

\begin{abstract}
Carbon dots materials (CDs) have the capability in the management of medical waste problem because of its advantage in the detection and degradation of pollutants. The synthesized CDs through various processes and raw materials have been applied to medical wastes, especially antibiotics such as tetracycline (TC), amoxicillin (AMX), paraNitrophenol (p-NP), doxycycline (DC), ciprofloxacin (CIP), and oxytetracycline (OTC). These antibiotics are detected by utilizing changes in the luminescence property of CDs from the turn-off and turn-on mechanisms. Afterward, the degradation process is conducted using CDs as support materials agent semiconductors in the photosynthesis scheme. In general, CDs can be referred to as multifunction smart materials with the ability to detecting the presence of the antibiotics in simple, sensitive, and selective ways, and potency of medical pollutant removal clearly and effectively.
\end{abstract}

Keywords. Carbon dots; medical waste; antibiotics sensing; removal

\section{Introduction}

Antibiotics are a type of drug that has been used to treat infections for decades [1]. In Indonesia, antibiotics are one of the contributors to water pollution. Pollution caused by antibiotics is relatively high because it is easily accessed by people in pharmacies and drug stores. During that time, antibiotic residues become a source of pollutants even in low concentrations. The residues are excreted through feces and urine after going through the metabolic process of the patient's body and polluting the water environment directly [3]. The first step that must be taken before removing antibiotic pollutants is to detect their

\footnotetext{
*Corresponding author: herisutanto@live.undip.ac.id
} 
presence. Several methods have been developed including high performance liquid chromatography-mass spectra (HPLC-MS) [4], enzyme-linked immunosorbent assays (ELISA) [5], surface-enhanced Raman scattering (SERS), electrochemistry, and colorimetry[6]. These methods require complicated instruments, high costs, and a long process. Therefore, a new simpler breakthrough with high sensitivity is needed. After the contaminations are detected, the next step that needs to be undertaken to resolve the problem completely is degradation.

Carbon dots (C-Dots) are unique materials with low toxicity [8] and attractive optical properties. CDs have been applied to various fields, such as energy [7, 8], health [9, 10], and environment $[11,12]$. Several optical advantages possessed by CDs cause these materials to be thoroughly studied and developed $[13,14]$. In this paper, the review of the latest developments in the application of CDs in processing waste material, especially in the detection and degradation of antibiotic residues will be presented.

\section{CDs as Sensors}

\subsection{Tetracycline Sensing}

CDs are often referred to as smart materials because of their optical properties that can be utilized in various applications. In the liquid waste sensor application, the optical properties employed are changes in the intensity of luminaries/emissions/luminescence from CDs.

The presence of tetracycline (TC) contamination in an aqueous environment can be detected by CDs. Yan et al. reported the results of the synthesis of CDs by traditional methods performed at room temperature following the principle of condensation. The results showed that luminescence emitted by CDs can be extinguished by TC. The changes in fluorescence intensity have a linear relationship with TC concentrations, where the detection limit is $6.0 \mathrm{mM}$ [15]. The decrease in TC luminous intensity is raised by the turn off mechanism which is influenced by the Innerfilter effect (IFE). To increase their sensitivity, Xing et al have modified CDs with sulfur-nitrogen doping (S, N-CDs) with urea and citric acid (CA) as precursors. S, N-CD fluorescence at a wavelength of $440 \mathrm{~nm}$ can be selectively extinguished by antibiotics through the mechanism of the IFE. In TC materials, maximum fluorescence at $600 \mathrm{~nm}$ is used as an internal standard signal because it produces a fluorometric spectral response. The application of S, N-CDs material for TC detection has a LOD limit in the range of $0.25 \mu \mathrm{M}$ [16].

Al hazimi et al have studied the manufacture of milk-based CDs that are capable to detect TC up to the detection limit of $0.6 \mathrm{mM}$. Afterward, Miao et al. observed the synthesized CDs through hydrothermal process using tobacco as a carbon source. In this observation, CDs were applied to detect three different types of antibiotics. The emission results showed that each antibiotic has a different interaction with CDs. CDs emissions were extinguished by TC without any fluorescence shift $(\mathrm{Em}=440 \mathrm{~nm}$, weak blue). Chlortetracycline (CTC) showed the phenomenon of blue shift $(\mathrm{Em}=415 \mathrm{~nm}$, colored blue) against fluorescence of CDs, while oxytetracycline (OTC) showed the phenomenon of red changes $(E m=500 \mathrm{~nm}$, yellowish-green $)$ on CDs emissions. This phenomenon is associated with the effect of changes in the enlarged energy bandgap for CTC and changes in the energy bandgap that narrows for OTC. For all three types of antibiotics, it showed a turnoff mechanism, where the higher the concentration of antibiotics, the decrease the intensity of CDs emissions (dim) [18].

\subsection{Amoxicillin Sensing}


Wang et al have reported that CDS is processed by a hydrothermal method based on dry beet powder without additional chemical reagents. In that study, CDs were 4-8 nm in diameter with carboxyl and hydroxyl surface functional groups. The result of photoluminescence (PL) intensity $I / I 0$ ratio exhibited a linear correlation between fluorescence intensity and AMX concentration, with the linear equation $I / I=0.99618+$ $0.01352[A M X]$. The intensity of PL I/IO showed a linear response with AMX concentrations in the range of $0-400 \mu \mathrm{M}$ and the detection limit is more at $0.475 \mu \mathrm{M}$. Visually, AMX can be detected using CDs because it increases the intensity of fluorescence CDs. [19]. Another research has detected AMX using boron-doped CDs (B-CDs) [20]. BCDs are synthesized by mixing citric acid and boric acid with the hydropyrolysis method. A quantum yield of $30.85 \%$ was obtained and fluorescence can sense AMX sensitively in the range of 1.43-429.12 $\mu \mathrm{mol} \cdot \mathrm{L}^{-1}$. The AMX mechanism detected by B-CDs showed that their combination is spontaneous with interactions forming hydrogen bonds between molecules. The advantage of using CDs in AMX detection is fluorescence which is only affected by AMX and is not affected by common metal ions, amino acids, and saccharides [20].

\subsection{Other Antibiotics}

Other antibiotic medical contaminants, such as para-Nitrophenol (p-NP), doxycycline (DC), Ciprofloxacin (CIP), and oxytetracycline (OTC) can also be detected with CDs. Sewage sludge-based CDs have been prepared using the microwave irradiation method. These CDs showed a quantum yield (QY) of up to $21.7 \%$ and can detect p-NPs in the linear detection range of $0.2-20 \mu \mathrm{M}$, while the detection limit is $0.069 \mu \mathrm{M}$ [21]. Thereafter, the modified CDs can detect the presence of doxycycline (DC) and oxytetracycline (OTC) with detection limits of 0.39 and $0.26 \mu \mathrm{M}$, respectively [16].

Besides, CDs synthesized from selenious yeast and riboflavin were able to detect the presence of Ciprofloxacin up to the limit of $0.13 \mu \mathrm{M}$ [22], while CDs modified by Bipyridine and Copper were able to detect the presence of Ciprofloxacin up to the limit of $0.4 \mathrm{nM}$ [23]. Generally, changes in CD fluorescence in the environment of liquid medical waste can be caused by electron transfer, IFE, fluorescence resonance energy transfer (FRET), as well as static and dynamic quenching effects [21]. Table 1 shows the summarization of several properties of CDs in the application of removing pollutants as antibiotics sensors. The schematic image of CDs as a sensor is represented in Figure 1.

Table 1. CDs application as antibiotics sensor

\begin{tabular}{llllll}
\hline Pollutants & Materials & Fluorescence & Method & $\begin{array}{l}\text { Limit } \\
\text { Detection }\end{array}$ & of \\
& & & Ref \\
\hline Amoxicillin & B-CDs & Blue & Hydropyrolysis & $0.825 \mu \mathrm{mol} \cdot \mathrm{L}^{-1}$ & 20 \\
Amoxicillin & CDs & Green & Hydrothermal & $0.475 \mu \mathrm{M}$ & 19 \\
Tetracycline & S, N-CDs & Blue & Hydrothermal & $0.25 \mu \mathrm{M}$ & 16 \\
Doxycycline & S, N-CDs & Blue & Hydrothermal & $0.39 \mu \mathrm{M}$ & 16 \\
Oxytetracycline & S, N-CDs & Blue & Hydrothermal & $0.26 \mu \mathrm{M}$ & 16 \\
Tetracycline & CDs & Green-yellow & Room & $6.0 \mathrm{mM}$ & 15 \\
& & & temperature & & \\
& & & condensation & & \\
Tetracycline & CDs & Weak blue & Hydrothermal & $5,18 \mathrm{nM}$ & 18 \\
Oxytetracycline & CDs & Green-yellow & Hydrothermal & $6,06 \mathrm{nM}$ & 18 \\
Chlortetracycline & CDs & Blue & Hydrothermal & $14 \mathrm{nM}$ & 18 \\
Ciprofloxacin & CDs & Blue-green & Hydrothermal & $0.13 \mu \mathrm{M}$ & 22 \\
Tetracycline & CDs & Greenish blue & Solvothermal & $0,6 \mathrm{mM}$ & 17 \\
Ciprofloxacin & CDs & Blue & & $0.4 \mathrm{nM}$ & 23 \\
\hline
\end{tabular}




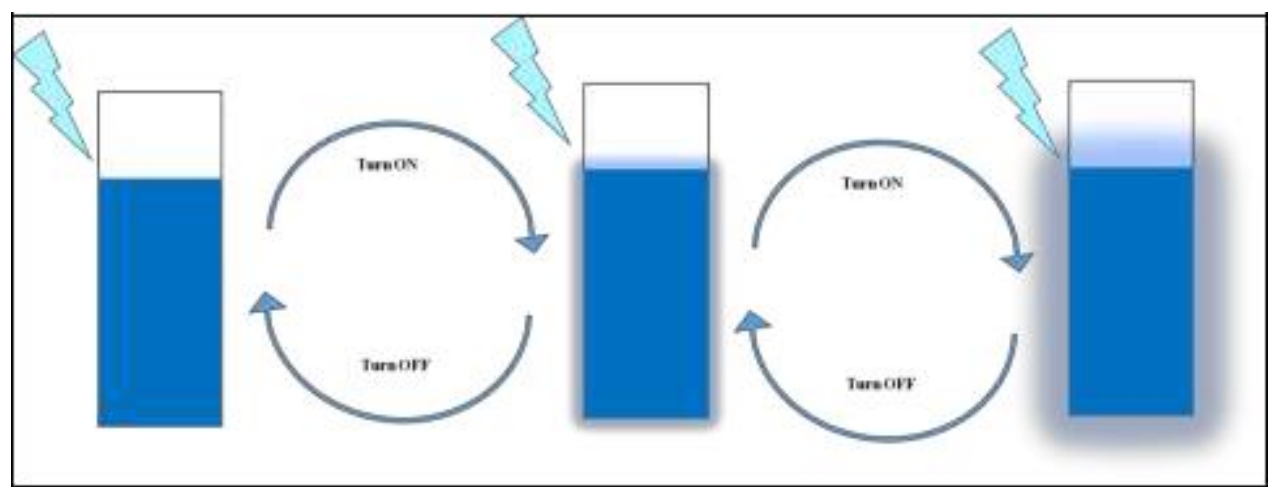

Fig. 1. Schematic application of CDs as sensors

\section{Medical Waste Degradation Using CDs}

In general, medical liquid waste of medical drugs is excreted through urine and feces that cannot be modified, impacting water pollution. The drunken water by organisms will be contaminated by liquid medical waste if water processing still carried out conventionally. This condition also affects human health. Several works such as adsorption, ozonation, degradation, electrolysis, and photocatalyst have been reported in the application of liquid medical waste removal in water [24].

Carbon dots (CDs) are novel carbon nanomaterials that displayed a good feature of photoluminescence conversion and produced a remarkable property of electron transfer and reservoir. This property enables photocatalyst to utilize sunlight efficiently [25]. CDs managed to be integrated with many semiconductors to improve the photocatalytic activity by decreasing the recombination of electron-hole and expanding photon absorption region. CDs can escalate photocatalytic property effectively in the degradation of liquid medical waste in the water.

The important things to consider in as photocatalysts are the ability to recombine electron and hole pairs. CDs materials are promising innovations in producing highefficiency photocatalyst materials [26] because CDs have the ability to both capture and transfer electrons as well as conventional semiconductor properties [27]. In the photocatalytic process, the surface of the CDs will absorb photons emitted by the light source. The absorbed photons are a source of energy to produce pairs of electrons and holes [28]. The hole will form when an electron is excited from the valence band to the conduction band. In the process, it will react with water or hydroxyl ions to form hydroxyl radicals. These hydroxyl radicals are very active in attacking organic molecules and lowering them into more friendly substances such as $\mathrm{CO} 2$ and $\mathrm{H} 2 \mathrm{O}$ [29]. Figure 2 represents the process of degradation with CDs assisted. 


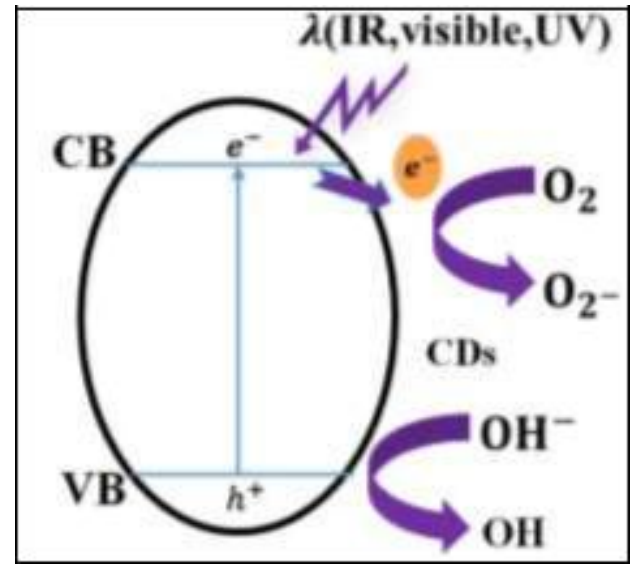

Fig. 2. Process of degradation using CDs.

\subsection{Tetracycline Removal}

Some materials have been delivered to be applied in the degradation or photocatalyst process of liquid medical waste. Ag+-CDs-Bi2WO6 was prepared using the impregnation hydrothermal method in lowering tetracycline content in water. TC is the second most used antibiotic in the world. The use of TC is widely used to treat various diseases. Besides, TC is widely used in the livestock industry $[30,31]$. TC in the water environment always carries a negative impact on human health and a balanced ecosystem.

$5 \mathrm{Ag}+-\mathrm{CDs} 2.5$-Bi2WO6 $(0.5 \mathrm{~g} / \mathrm{L})$ materials showed a photocatalytic efficiency that is capable of removing almost $100 \%$ of TC $(20 \mathrm{mg} / \mathrm{L})$ within 20 minutes and $64 \%$ of mineralization in 90 minutes. The degradation capability of these materials was about 1.8 times higher than pure Bi2WO6 materials as result from the synergistic effect of $\mathrm{Ag}+$ and $\mathrm{CD}$ which are doped in the surface of Bi2WO6 [32]. Octahedral $\mathrm{CoO}$ materials were produced with a solvothermal method using CDs catalyst as the stabilizer. The photocatalytic activity of $\mathrm{CDs} / \mathrm{CoO}$ composite in the TC degradation was $87 \%$ in 60 minutes and remained stable for 5 degradation cycles. $\mathrm{CDs}$ in the $\mathrm{CDs} / \mathrm{CoO}$ composite were not only able to increase the efficiency of electron charges separation but also strengthen the interaction between $\mathrm{CDs}$ and a very reactive $\mathrm{CoO}$ octahedron material [33]. Another research using a solvothermal process with a different product is a study by Jun, et al. [34]. In their research, $\mathrm{Ag} / \mathrm{CDs} / \mathrm{BiOCl}$ materials were derived for $\mathrm{TC}$ degradation application with a result of removal effectivity of $68.9 \%$ within 50 minutes. The application of $\mathrm{Ag}$ and $\mathrm{CDs}$ was performed to increasing the visible light response from $\mathrm{BiOCl}$ and electron transfer and separation, so asto improve the performance of photocatalyst. Weilong, et al. reported the precipitation-photoreduction process to deliver $\mathrm{CDs} / \mathrm{Ag} / \mathrm{AgBr}$ with strong absorption in the visible light spectrum that relies on nanoparticle interaction of $\mathrm{Ag}$ and CDs. The nanoparticles were able to degrade $100 \%$ of TC under irradiation of infrared light for 30 minutes. Significantly, a very good photocatalytic performance in these nanomaterials was in relation to a broad light absorbance, effective charges separation, and increasing synergetic of Plasmon surface resonance of Ag nanoparticles [35].

Graphitic carbon nitride (g-C3N4) is a conjugated free metal-polymer that widely applied as photocatalyst materials. Research has been prepared Ag/CDs/g-C3N4 nanocomposite to degrade TC under visible light with an efficiency of $93.4 \%$ in 60 minutes. The application of Ag that has an SPR effect will improve the photocatalytic effectivity. Moreover, the addition of CDs can increase the light absorbance efficiency, 
speed up the electron transfer process, and as an electron reservoir media. Ag/CDs/g-C3N4 materials are still stable for 5 cycles [36].

A different method, thermal-impregnation, was conducted to produce $\mathrm{CDs} / \mathrm{g}-\mathrm{C} 3 \mathrm{~N} 4 / \mathrm{ZnO}$ nanocomposite that exhibits a photocatalytic activity in TC degradation with $100 \%$ effectivity within 30 minutes of the process. The coated CDs on the surface of $g-C 3 N 4 / Z n O$ heterojunction improved the visible light response and separation efficiency of the holeelectron pair because of the electron transfer. Besides, radical oxide $(\mathrm{O} 2)$ and hydroxyl $(\mathrm{OH})$ were formed on the surface of photocatalyst when the degradation step was conducted [37]. Furthermore, the addition of $0.5 \% \mathrm{CDs}$ doping in $\mathrm{g}-\mathrm{C} 3 \mathrm{~N} 4 / \mathrm{MoO} 3$ was afforded to degrade $81 \%$ of TC for 90 minutes under the irradiation of visible light. This capability is a synergetic effect from CDs properties which is a great UPPL (Up Photoluminescence) and high charge separation capacity. The experiment showed that scheme-Z CDs doped in g$\mathrm{C} 3 \mathrm{~N} 4 / \mathrm{MoO} 3$ results in a promising photocatalyst on $\mathrm{TC}$ removal from the water environment [38].

Sulfur doping carbon dots (S-CDs)/hollow tubular g-C3N4 hybrids (HTCN-C) was successfully fabricated using the ultrasonic method as an efficient catalyst on the TC degradation in the wastewater system. In the photocatalytic system, S-CDs work as photosensitizer and electron mediator in the expanding the photon absorbance region and decreasing recombination carrier induced by photon. HTCN-C was produced through molecular design between melamine and cyanuric acid. A unique hollow tubular structure of g-C3N4 and CDs intensified the electron transfer and charge separation, that head to a significant increase in photocatalytic efficiency and superior performance with a reaction rate of 0.0293 per minute for TC degradation of $82.67 \%$ under irradiation of visible light for 60 minutes. HTCN-C provides innovations for the design of photocatalyst based on 0D/1D g-C3N4 with nanostructures for practical wastewater treatment in TC degradation [39].

$\mathrm{N}-\mathrm{CDs} / \mathrm{Ag} 3 \mathrm{PO} 4$ materials were applied on the BiVO4 surface by chemical bonds using the precipitation-solvothermal method. Photocatalytic activity of photocatalyst was employed for the degradation of TC under visible light illumination. The results showed an increase in photocatalytic efficiency of BiVO4/N-CDs/Ag3PO4-10 (Ag3PO4 with a mass ratio of $\mathrm{BiVO} 4 / \mathrm{N}-\mathrm{CQs} / \mathrm{Ag} 3 \mathrm{PO} 4=10 \%)$ for $\mathrm{TC}$ degradation $(10 \mathrm{mg} / \mathrm{L})$ reaching $88.9 \%$ within 30 minutes and 59.8\% mineralization within 90 minutes. The excellent photocatalytic performance BiVO4/N-CDs/Ag3PO4 is associated with the construction of the Z-scheme system. The Z-schematic system formed is considered to originate from $\mathrm{N}$ CDs which can transfer and collect electrons very well $[40,41]$. This not only results in enhanced efficiency of the electron-hole pairing but also maintains a strong redox reaction capability. In addition, the use of N-CDs and Ag3PO4 on BiVO4 surfaces can result in increased visible light absorption capability. Mainly, N-CDs can act as photosensitizers and photon centers to absorb light. Then, the molecular oxygen activation ability of N-CDs contributed to the efficiency of photocatalytic degradation which is very good [42].

Meanwhile, ZIS/CDs material can also be applied to degrade liquid medical waste. ZIS/CDs were processed by a simple in-situ hydrothermal method. These materials were used to degrade tetracycline hydrochloride $(\mathrm{TCH})$ under UV light, visible light, NIR light, and simulation of solar irradiation. ZIS/CDs were capable to degrade $100 \%$ of TCH under NIR light for 40 minutes. Monodispersion CDs were evenly embedded into the nanosheets that make up the ZnIn2S4 nanoflower. ZnIn2S4/CDs obtained by nanohybrid points with the absorption capacity of a broad spectrum of sunlight showed excellent photocatalytic UV-vis-NIR light activity for $\mathrm{TCH}$ in stable aqueous and photocatalytic solutions. Enhanced UV-vis-NIR photocatalytic properties can be attributed to UPPL conversion properties, extended optical absorption, and efficient charge separation and transfer by the addition of CDs [43]. 
Another study that has been carried out is a fabrication by a one-pot microwave method with CDs, glycerol, and urea (GUCD) as sources. Carbon nanoparticles (GUCD) showed good performance and interesting neon features where selective interactions occur with TC grade antibiotics. The nature of this interaction is considered to originate from static cooling and appeared to originate from the formation of complex basic conditions between TC and GUCD which are successfully applied to the determination of tetracycline in urine samples with good recovery (around 94.7-100\%) [44]. Else from previous, CDs sensitized 2D-2D heterojunction of $\mathrm{BiVO} 4 / \mathrm{Bi} 3 \mathrm{TaO} 7$ was yielded from a simple hydrothermal method [18]. The prepared $\mathrm{CDs} / \mathrm{BiVO} 4 / \mathrm{Bi} 3 \mathrm{TaO} 7$ showed superior performance for the degradation of various antibiotics under visible light illumination. The level of photodegradation obtained was $91.7 \%$ for tetracycline (TC) and stable for ten times experimental recycles [45].

\subsection{Amoxicillin Removal}

In addition to tetracycline degradation, several materials processings for the degradation of other liquid medical wastes have been carried out. Carbon dots (CDs) mediated by $\mathrm{Sn} 2 \mathrm{Ta} 2 \mathrm{O} 7 / \mathrm{SnO} 2$ heterostructured sponges were successfully synthesized by a simple hydrothermal method for amoxicillin (AMX) degradation with photocatalytic efficiency against AMX estimated at $88.3 \%$ for 120 minutes under sunlight radiation and have stability for reuse under simulated sunlight over a wider $\mathrm{pH}$ range from acids, bases, and natural conditions. With the modification of CDs, it is able to enhance the effectiveness of photocatalyst by utilizing sunlight that has long wavelengths due to up-fluxing photoluminescence (UCPL). Besides, the porous structure and the small number of dots on carbon increased the adsorption ability by increasing the specific surface area. Furthermore, CDs mediate Z-type heterojunction from $\mathrm{Sn} 2 \mathrm{Ta} 2 \mathrm{O} 7$. SnO2 facilitated efficient photoninduced separation and transfer carriers [46].

Carbon dot composites were successfully modified in potassium nanotube potassium titanate (CDs/K2Ti6O13) as photocatalyst by the hydrothermal method combined with the calcination stage. The photocatalytic performance of CDs/K2Ti6O13 for AMX degradation under irradiation of visible light and lamps with wavelengths of 365, 385, 420, 450, 485, 520,595 , and $630 \mathrm{~nm}$. The narrowing energy bandgap $(E g)$ and the increased photonelectron transfer by CDs inhibited the direct combination of the electron-hole pair, so as to increase photocatalytic activity. CDs/K2Ti6O13 showed good reusability for photocatalytic degradation of AMX after five consecutive times. The photocatalytic activity of composite $\mathrm{CDs} / \mathrm{K} 2 \mathrm{Ti6O} 13$ is greatly increased under UV light and visible light irradiation. The $\mathrm{CDs} / \mathrm{K} 2 \mathrm{Ti6O13}$ composite showed high AMX degradation efficiency through photocatalysis ie after 90 minutes of irradiation of sunlight at wavelengths of $365 \mathrm{~nm}$ and $385 \mathrm{~nm}, \mathrm{AMX}$ was completely removed by CDs/K2Ti6O13 [47].

NZVI composites were doped with biopolymer-based CDs to increase their stability/utilization ratio and decrease agglomeration as a photocatalyst material. The synthesis method used is simple hydrothermal, which is the preparation and stabilization of $\mathrm{Fe}^{0}$ nanoparticles carried out simultaneously. CDs obtained from the carbonization of Gum Tragacanth reduced iron salts and produce $\mathrm{Fe}^{0}$, and act as capping agents for $\mathrm{Fe} 0$. NZVI / CDs are used to degrade AMX [48]. Otherwise, Shukun et al. studied CDs sensitized 2D2D heterojunction of $\mathrm{BiVO} 4 / \mathrm{Bi} 3 \mathrm{TaO} 7$ with a simple hydrothermal method besides being used to degrade TC, it is also used for AMX degradation. CDs/BiVO4/Bi3TaO7 $\mathrm{Bi} 3 \mathrm{TaO} 7$ materials can degrade $89.3 \%$ of amoxicillin [45]. 


\subsection{Ciprofloxacin Removal}

$\mathrm{ZnO}$ is widely used as a photocatalyst in industry. However, it is still a challenge to degrade liquid medical waste, especially antibiotics in water using $\mathrm{ZnO}$. N,S-doped carbon dot (N,S-CDs) has been performed with a one-pot hydrothermal method, N,S-CDs using Lcysteine as carbon source and ethylene glycol as passivation agent. N, S-CDs that have been synthesized were planted in $\mathrm{ZnO}$ for the formation of hybrid nanoflowers $(\mathrm{ZnO} / \mathrm{N}, \mathrm{S}-$ CDs).

This material exhibited significantly increased photocatalytic activity under visible light. About $92.9 \%$ and $85.8 \%$ of ciprofloxacin (CIP) were able to be degraded by $\mathrm{ZnO} / \mathrm{N}$, S-CDs which were simulated in sunlight and the results showed that surface functionalization, electron transfer, luminescence converted to N, S-CDs properties making a major contribution to the increased photocatalytic activity of $\mathrm{ZnO} / \mathrm{N}, \mathrm{S}-\mathrm{CDs}$ [49].

NZVI composites doped with CDs not only work to degrade AMX but can also degrade CIP. However, the reduction of AMX by NZVI/CDs catalysts is more efficient than CIP. This is because there is more reactivity of AMX's molecular structure and CIP's tendency to form complexes with iron ions under certain conditions. In addition, the low reactivity of protonated amines (a cationic form of CIP) against hydroxyl radicals in acidic $\mathrm{pH}$ is one of the possible explanations for the removal of lower CIP [48].

Heterojunction 2D-2D CDs were prepared with $\mathrm{BiVO} 4 / \mathrm{Bi} 3 \mathrm{TaO} 7$ with a simple hydrothermal method. The prepared $\mathrm{CDs} / \mathrm{BiVO} 4 \mathrm{Bi} 3 \mathrm{TaO} 7$ showed superior performance for the degradation of various antibiotics under visible light illumination. Beside degrading TC dan AMX, CDs/BiVO4/Bi3TaO7 were also able to degrade CIP by as much as $87.1 \%$ and stable for ten times of experimental recycling. Furthermore, by assessing the mixture of TC, AMX, and CIP antibiotic solutions, it was proposed that the prepared samples are potentially effective for liquid medical waste. Increasing photocatalytic activity can be attributed to the unique structure of heterojunction mediated CDs, which can accelerate electron migration and molecular oxygen activation, also increase light-harvesting capacity he efficiency of charge separation. This investigation can provide a new perspective for heterojunction mediated CDs design that could be a potential photocatalyst for the application of liquid medical waste degradation [45]. Table 2 shows some application of CDs in the removal of medical waste.

Table 2. Applications of CDs as medical waste removal

\begin{tabular}{|c|c|c|c|c|}
\hline $\begin{array}{l}\text { Pollutants } \\
\text { [Ref] }\end{array}$ & Materials & Method & $\begin{array}{l}\text { Removal } \\
\text { Conditions } \\
\end{array}$ & $\begin{array}{l}\text { Efficiency } \\
(\%)\end{array}$ \\
\hline $\mathrm{TC}[32]$ & $5 \mathrm{Ag}^{+}-\mathrm{CDs} 2.5-\mathrm{Bi}_{2} \mathrm{WO}_{6}$ & Hydrothermal & $\begin{array}{l}\text { Xe flash for } 20 \\
\text { minutes }\end{array}$ & 100 \\
\hline TC [33] & $\mathrm{CDs}-\mathrm{CoO}$ & Solvothermal & $\begin{array}{l}\text { Visible light for } \\
60 \text { minutes }\end{array}$ & 87 \\
\hline $\mathrm{TC}[34]$ & $\mathrm{Ag} / \mathrm{CDs} / \mathrm{BiOCl}$ & Solvothermal & $\begin{array}{l}\text { Visible light for } \\
50 \text { minutes }\end{array}$ & 68.9 \\
\hline $\mathrm{TC}[35]$ & $\mathrm{CDs} / \mathrm{Ag} / \mathrm{AgBr}$ & $\begin{array}{l}\text { Precipitation- } \\
\text { photoreduction }\end{array}$ & $\begin{array}{l}\text { Near-infrared } \\
\text { light for } 30 \\
\text { minutes }\end{array}$ & 100 \\
\hline $\mathrm{TC}[36]$ & $\mathrm{Ag} / \mathrm{CDs} / \mathrm{g}-\mathrm{C}_{3} \mathrm{~N}_{4}$ & $\begin{array}{l}\text { Precipitation- } \\
\text { photoreduction }\end{array}$ & $\begin{array}{l}\text { Visible light for } \\
60 \text { minutes }\end{array}$ & 93.4 \\
\hline TC [37] & $\mathrm{CDs} / \mathrm{g}-\mathrm{C}_{3} \mathrm{~N}_{4} / \mathrm{ZnO}$ & $\begin{array}{l}\text { Thermal- } \\
\text { impregnation }\end{array}$ & $\begin{array}{l}\text { Visible light for } \\
30 \text { minutes }\end{array}$ & 100 \\
\hline TC [38] & $\mathrm{CDs} / \mathrm{g}-\mathrm{C}_{3} \mathrm{~N}_{4} / \mathrm{MoO}_{3}$ & Hydrothermal & $\begin{array}{l}\text { Visible light for } \\
90 \text { minutes }\end{array}$ & 81 \\
\hline TC [39] & $\mathrm{S}-\mathrm{CDs} /$ hollow tubular g- $\mathrm{C}_{3} \mathrm{~N}_{4}$ & Ultrasonic & $\begin{array}{l}\text { Visible light for } \\
60 \text { minutes }\end{array}$ & 82.67 \\
\hline
\end{tabular}




\begin{tabular}{|c|c|c|c|c|}
\hline $\mathrm{TC}[42]$ & $\mathrm{BiVO}_{4} / \mathrm{N}-\mathrm{CDs} / \mathrm{Ag}_{3} \mathrm{PO}_{4-10}$ & $\begin{array}{l}\text { Precipitation- } \\
\text { solvothermal }\end{array}$ & $\begin{array}{l}\text { Visible light for } \\
30 \text { minutes }\end{array}$ & 88.9 \\
\hline TCH [43] & $\mathrm{ZIS} / \mathrm{CDs}$ & Hydrothermal & $\begin{array}{l}\text { Near-infrared } \\
\text { light for } 40 \\
\text { minutes }\end{array}$ & 100 \\
\hline TC [44] & GUCD & $\begin{array}{l}\text { One-pot } \\
\text { microwave }\end{array}$ & Visible light & $94.7-100$ \\
\hline $\mathrm{TC}[45]$ & $\mathrm{CDs} / \mathrm{BiVO}_{4} / \mathrm{Bi}_{3} \mathrm{TaO}_{7}$ & Hydrothermal & Visible light & 91.7 \\
\hline AMX [46] & $\mathrm{Sn}_{2} \mathrm{Ta}_{2} \mathrm{O}_{7} / \mathrm{SnO}_{2} / \mathrm{CDs}$ & Hydrothermal & $\begin{array}{l}\text { Visible light for } \\
120 \text { minutes }\end{array}$ & 88.3 \\
\hline AMX [47] & $\mathrm{CDs} / \mathrm{K}_{2} \mathrm{Ti}_{6} \mathrm{O}_{13}$ & Hydrothermal & $\begin{array}{l}\text { Visible light for } \\
90 \text { minutes }\end{array}$ & 100 \\
\hline AMX [48] & NZVI/CDs & Hydrothermal & & \\
\hline AMX [45] & $\mathrm{CDs} / \mathrm{BiVO}_{4} / \mathrm{Bi}_{3} \mathrm{TaO}_{7}$ & Hydrothermal & Visible light & 89.3 \\
\hline CIP [49] & $\mathrm{ZnO} / \mathrm{N}, \mathrm{S}-\mathrm{CDs}$ & $\begin{array}{l}\text { One-pot } \\
\text { hydrothermal }\end{array}$ & Visible light & 85.8 \\
\hline CIP [48] & $\mathrm{NZVI} / \mathrm{CDs}$ & Hydrothermal & & \\
\hline CIP [45] & $\mathrm{CDs} / \mathrm{BiVO}_{4} / \mathrm{Bi}_{3} \mathrm{TaO}_{7}$ & Hydrothermal & Visible light & 87.1 \\
\hline
\end{tabular}

\section{Conclusion}

Carbon dots (CDs) materials exhibit an excellent optical properties in the sensor and degradation application of antibiotics from medical waste. Previous research have succesfully produced CDs using several process with antibiotics removal efficiency until $100 \%$. Indeed, some of them deployed natural resources as carbon source. This works can be a good reference to fabricate sustainable smart materials.

\section{References}

1. M. Scheurell, S. Franke, R. Shah, H. Hühnerfuss, Chemosphere, 77, 870-6 (2009).

2. Kummerer, K., Chemosphere, 75, 435-441 (2009).

3. Q.Q. Zhang, G.G. Ying, C.G Pan, Y.S. Liu, J.L. Zhao, Environ. Sci. Technol, 49, 6772-6782 (2015).

4. F. Zarlaida, M. Adlim, Microchimica Acta, 184, 45-58 ( 2017).

5. B. Cao, G. He, H. Yang, H., Chang, S. Li, A, Talanta, 115, 624-630 (2013).

6. K. Shrivas, J. Sahu, P. Maji, D. Sinha, New Journal of Chemistry, 41:6685-92 (2017).

7. I. Alkian, A.Prasetio, L. Anggara, M.H. Fonisyah, Z.M. Rizka, H. Widiyandari, Journal of Physics: Conference Series, 1204(1), 012093 (2019).

8. C. Hu, M. Li, J. Qiu, Y.P. Sun, Chemical Society Reviews, 48(8), 2315-2337 (2019).

9. S. Chaudhary, A. Umar, K.K. Bhasin, S. Singh, Journal of Biomedical Nanotechnology, 13(6), 591-637 (2017).

10. H. Liu, L. Zhang, M. Yan, J. Yu, Journal of Materials Chemistry B, 5(32), 6437-6450 (2017).

11. M.Y. Pudza, Z.Z. Abidin, S. A. Rashid, F. Md. Yasin, A. S. M. Noor, M. A. Issa, Nanomaterials, 10(2), 315(2020).

12. I. W. Lewa, H. Sutanto, A. Subagio, I. Marhaendrajaya, H. Sugito, Materials Research Express, 6(10), 105703(2019).

13. X. Sun, Y. Lei, TrAC Trends in Analytical Chemistry, 89, 163-180 (2017).

14. H. Sutanto, I. Alkian, N. Romanda, I. W. L Lewa, I. Marhaendrajaya, P. Triadyaksa, AIP Advances, 10(5), 055008 (2020). 
15. Y. Yan, J.H. Liu, R.S. Li, Y.F. Li, C.Z. Huang, S.J. Zhen, Analytica Chimica Acta, 1063, 144-151 (2019).

16. X. Xing, X, L. Huang, S. Zhao, J. Xiao, M. Lan, Microchemical Journal, 105065(2020).

18. B. Al-Hashimi, K.M. Omer, H.S. Rahman, Arabian Journal of Chemistry, (2020). H. Miao, Y. Wang, X. Yang, Nanoscale, 10(17), 8139-8145(2018).

19. K. Wang, Q. Ji, J. Xu, H. Li, D. Zhang, X. Liu, H. Fan, Journal of Fluorescence, 28(3), 759-765 (2018).

20. X. Zhang, Y. Ren, Z. Ji, J. Fan, Journal of Molecular Liquids, 113278 (2020).

21. Y. Hu, Z. Gao, Journal of Hazardous Materials, 382, 121048 (2020).

22. C. Lu, G. Liu, Z. Yang, Y. Wang, H. Rao, W. Zhang, X. Wang, Microchimica Acta, 187(1), 37(2020).

23. V. D. Dang, A.B.Ganganboina, R.A. Doong, ACS Applied Materials \& Interfaces, (2020).

24. M.N. Chong, B. Jin, Christopher W.K. Chow, C. Saint, Water Res, 442.997 3.027(2010).

25. P. Chen, F. Wang, Z.F. Chen, Q. Zhang, Y. Su, L. Shen, K. Yao, Y. Liu, Z. Cai, W, Lv, Appl. Catal. B Environ, 204, 250-259 (2017).

26. R. Wang, K. Lu, Z. Tang, Y Xu, J Mater Chem A, 5 (37), 17-34 (2017).

27. A. Aghamali, M. Khosravi, H. Hamishehkar, N. Modirshahla, M. A. Behnajady, J Lumin, 201, 265-274 (2018).

28. E. Liu, C. Xu, C. Jin, J. Fan, X. Hu, J Taiwan Inst Chem Eng, 97, 316-325 (2019).

29. D. Syafei, S. Sugiarti, N. Darmawan, M. Khotib, Indones. J. Chem 17 (1). 37-42 (2017).

30. S.P. Kim, P. Eichhorn, J.N. Jensen, A.S. Weber, D.S. Aga, Environ, Sci. Technol, 39, 5816-5823 (2005).

31. L. Zhang, X.Y. Song, X.Y. Liu, L.J. Yang, F. Pan, J.N. Lv, Chem. Eng. J, 178, 26-33 (2011).

32. L. Zhuo, L. Zhu, W. Wu, S. Wang, L. Qiang, Applied Catalysis B: Environmental, 192, 277-285 (2016).

33. S. Weilong, F. Guoa, H. Wanga, M. Hana, H. Lia, S. Yuan,H. Huanga, Y. Liua, Z. Kanga, Applied Catalysis B: Environmental, 219, 36-44 (2017).

34. J. Zhang, Y. Guoa, Y. Xionga, D. Zhoub, S. Donga, Journal of Photochemistry and Photobiology A: Chemistry, 356, 411-417 (2018).

35. W. Shi, Huachang Lv, S.Yuan, H. Huang, Y. Liu, Z. Kang, Separation and Purification Technology, 174, 75-83 (2017).

36. S. Qu, Y. Xiong, Journal of Photochemistry \& Photobiology A: Chemistry, 365, 23-31 (2018).

37. F. Guo, W. Shi, W. Guan, H. Huang, Y. Liu, Separation and Purification Technology, 173, 295-303 (2017).

38. Z. Xie, Y. Feng, F. Wang, D. Chen, Q. Zhang, Y. Zeng, Wenying Lv, G. Liu, Applied Catalysis B: Environmental, 229, 96-104 (2018).

39. W. Wang, Z. Zeng, G. Zenga, C. Zhanga, R. Xiao C. Zhoua, W. Xionga, Y. Yanga, L. Leia, Y. Liua, D. Huanga, M. Chenga, Y. Fua, H. Luoa, Y. Zhoua, Chemical Engineering Journal, 378, 122-132 (2019).

40. F. Chen, Q. Yang, X. Li, G. Zeng, D. Wang, C. Niu, J. Zhao, H. An, T. Xie, Y. Deng, Appl. B: Environment, 200, 330-342 (2017).

42. C. Li, P. Zhang, R. Lv, J. Lu, T. Wang, S. Wang, H. Wang, J. Gong, Small 9, 23, 3951-3956 (2013).

43. J. Zhang, Jin, M. Yan, X. Yuan, M. Si, L. Jiang, Z. Wua, H. Wang, G. Zeng, Journal of Colloid and Interface Science, 529, 11-22 (2018). 
44. H. Xu, Y. Jiang, X. Yang, F. Li, A. Li, Y. Li, J. Zhang, Z. Zhou, L. Ni, Materials Research Bulletin, 97, 158-168 (2018)

45. D. Uriarte, C. Domini, M. Garrido, Talanta, 201, 143-148 (2019).

46. S. Le, W. Li, Y. Wang, X. Jiang, X. Yang, X. Wang, Journal of Hazardous Materials, 376, 1-11 (2019).

47. S. Le, W. Yang, G. Chen, A. Yan, X. Wang, Environmental Pollution, 263, 114550 (2020).

48. Q. Chen, L. Chena, J. Qia, Y. Tonga, Y. Lva, C. Xua, J. Nia, Wen Liua, Chemical Letters, 30, 1214-1218 (2019).

49. M. Pirshaheb, S. Moradi, M. Shahlaei, X. Wang, N. Farhadian, 209, 1523-1532 (2019).

50. Y. Qu, X. Xua, R. Huang, W. Qia, R. Sua, Z. Hea, Chemical Engineering Journal, 382, 123016 (2020). 